\title{
Determination of Bendamustine in Human Plasma and Urine by LC-FL Methods: Application in a Drug Monitoring
}

\author{
Alina Plenis ${ }^{1} \cdot$ Agnieszka Frolow $^{1} \cdot$ Natalia Rekowska $^{1} \cdot$ Ilona Olędzka $^{1} \cdot$ \\ Piotr Kowalski ${ }^{1}$ Ewa Bieñ ${ }^{2}$ - Małgorzata Anna Krawczyk ${ }^{2}$. \\ Elżbieta Adamkiewicz-Drożynska ${ }^{2}$ Tomasz Bączek ${ }^{1}$
}

Received: 2 March 2016 / Revised: 28 April 2016 / Accepted: 9 May 2016 / Published online: 18 May 2016

(C) The Author(s) 2016. This article is published with open access at Springerlink.com

\begin{abstract}
Simple and sensitive liquid chromatography (LC) methods with fluorescence (FL) detection for the determination of bendamustine (BM) in human plasma and urine were developed and validated. The procedure of BM extraction from a plasma sample involved solid-phase extraction with a C18 SPE column, while liquid-liquid extraction with dichloromethane was applied for a urine sample. In both methods, cinoxacin was used as the internal standard. Chromatographic separations were performed on a Synergi Max-RP column, while FL detector was set at the excitation wavelength of $328 \mathrm{~nm}$ and the emission wavelength of $420 \mathrm{~nm}$. The LC-FL methods were validated for accuracy, precision, selectivity, linearity, recovery, and stability. The detection limits for BM were 0.5 and $2.5 \mathrm{ng} \mathrm{mL}^{-1}$ in plasma and urine, respectively. The intraday and inter-day precisions were less than $9.86 \%$, while the accuracies were higher than 92.63 and $94.29 \%$ for BM in plasma and urine, respectively. The proposed LC-FL methods were sensitive, robust, and specific, allowing reliable drug quantification in plasma and urine samples. The methodologies were successfully applied to monitoring of $\mathrm{BM}$ in a child with cancer treated with BM.
\end{abstract}

Electronic supplementary material The online version of this article (doi:10.1007/s10337-016-3103-3) contains supplementary material, which is available to authorized users.

Alina Plenis

aplenis@gumed.edu.pl

1 Department of Pharmaceutical Chemistry, Medical University of Gdansk, Hallera 107, 80-416 Gdansk, Poland

2 Department of Pediatris, Hematology and Oncology; Medical University Gdansk, Debinki 7, 80-11 Gdansk, Poland
Keywords Bendamustine $\cdot$ Biological samples $\cdot$ Sample preparation $\cdot$ LC determination $\cdot$ Fluorescence detection . Drug monitoring

\section{Introduction}

Bendamustine (bendamustine hydrochloride) (BM) (4-[5-[bis-(2-chloroethyl)amino]-1-methyl-benzimidazol2-yl]butyric acid hydrochloride is a unique alkylating agent, which combines a nitrogen mustard moiety of mechlorethamine with a benzimidazole (Fig. 1) [1]. This cytostatic agent has been used in Germany since the 1970s against a number of malignancies [2, 3]. In 2008, BM was approved in the US for the treatment of chronic lymphocytic leukemia (CLL) and later for indolent B cell non-Hodgkin's lymphoma (NHL) $[4,5]$. The mechanism of action of BM is unique and multifaceted. Compared to other alkylating agents, BM causes more extensive and long-lasting DNA damage which leads to a concentration-dependent apoptosis and non-apoptotic cell death or mitotic catastrophe [68]. Thus, many clinical trials have recently focused on the assessment of the optimal dosage, tolerance, and efficacy of BM in various hematological and some solid malignancies, including: CLL, NHL, Hodgkin's disease, multiple myeloma, primary and metastatic brain tumors, small-cell lung cancer sarcomas, and other neoplasms [9-14]. Preclinical and clinical studies have shown that BM demonstrates no complete cross-resistance with the conventional alkylating agents, which may explain its efficacy in heavily pretreated, relapsed, and/or progressive malignancies [15].

BM can be used as a single agent or in combination with other anti-cancer agents $[16,17]$. Although various BM dosing schemes have been attempted, the most typical protocol consists in administering BM intravenously on 


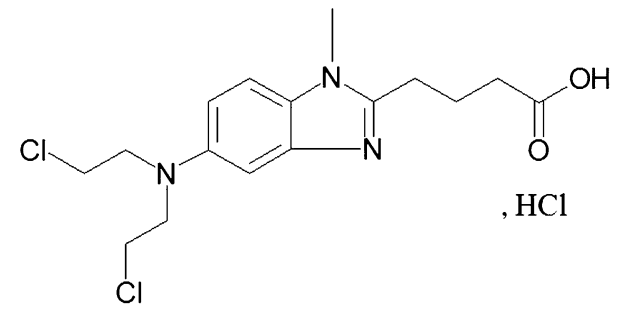

Fig. 1 Chemical structure of bendamustine hydrochloride (BM)

two consecutive days, every 28 days, in the dose of 100 $120 \mathrm{mg}\left(\mathrm{m}^{2}\right)^{-1}$ body surface per day.

The most common side effects associated with BM include hematological events, such as leukopenia, neutropenia, thrombocytopenia, and anemia and gastrointestinal complications [18, 19]. It should be noted that the major route of BM metabolism is its hydrolysis to inactive products which add little or nothing to the anti-cancer effects of BM [16]. Thus, clinical activity against a variety of hematological malignancies and solid tumors is mainly related to the concentration of the parent substance, which indicates that its dosage should be carefully adjusted for the treatment of patients with a particular type of cancer [20-23]. Moreover, clinical trials on the use of BM in cancer children are seldom described, which increase the risk of incorrect drug administration $[24,25]$. Therefore, it is important to monitor the BM concentration in biological fluids to optimize efficacy and minimize any adverse effects [26].

To the best of our knowledge, only a few analytical techniques have been developed for the quantification of BM in the presence of its metabolites in plasma [23, 27-29], urine [23, 27-31], bile [23, 31, 32], or mouse brain tissue [33]. Among them, liquid chromatography (LC) coupled with mass spectrometry (MS) has been the most widely used technique [22, 23, 27, 29-33]. Unfortunately, these methodologies are scarred with a number of limitations, such as long analysis time and no validation data $[22,23,27,30$ 32], 100-fold dilution of the urine sample with plasma [29], and low recovery of BM from brain tissue [33]. In addition, LC methods with fluorescence (FL) detection have been reported for the monitoring of BM in biological fluids in the presence of its metabolites [22, 23, 28, 31, 32], respectively. However, those LC-FL techniques suffer from insufficient validation information [22, 23, 31, 32] and low efficiency of the extraction procedure [28].

The aim of this study was to develop rapid, cost-effective, and sensitive LC methods with FL detection, in combination with simple sample preparation procedures suitable for the quantification of BM in human plasma and urine, which could be accessible to most pharmaceutical and clinical laboratories offering interesting alternatives to the previously published methodologies. The utility of the proposed LC-FL methods was demonstrated through their application to monitor BM in a pediatric cancer patient.

\section{Materials and Methods}

\section{Reagents}

Bendamustine hydrochloride (99.8 \% purity) was supplied by Tocris (Bristol, United Kingdom). Cinoxacin (internal standard, I.S.) (99.8\% purity) came from Sigma Aldrich (St. Louis, MO, USA). Ortho-phosphoric acid $85 \%$ and hydrochloric acid $36 \%$ of the analytical grade were purchased from POCh (Gliwice, Poland). HPLC grade acetonitrile, methanol, and dichloromethane were supplied by Merck (Darmstadt, Germany). The organic solvents and reagents used for sample preparation and the mobile phase were used as received without further purification. The water used in all experiments was purified with the MilliQ system (Molsheim, France). LiChrolut RP-18 cartridges (100 mg, $1 \mathrm{~mL}$ ) were purchased from Merck (Darmstadt, Germany). The control plasma and urine were obtained from healthy volunteers.

\section{Chromatographic Conditions}

All LC measurements were performed on an ACME 9000 system (Younglin Instrument Corporation, Anyang, The Republic of Korea) equipped with a pump (SP 930D), fluorescence detector RF-551 (Shimadzu, Japan), autosampler, thermostat (CTS30), and computer system for data acquisition (AutoChro-3000). Chromatographic separation was carried out on a Synergi Max-RP column $(150 \times 4.6 \mathrm{~mm}$, $4 \mu \mathrm{m}$ ) from Phenomenex (Torrance, CA, USA) with a binary mixture of acetonitrile-water (25:75, v/v) adjusted to $\mathrm{pH} 2.7$ with $85 \%$ ortho-phosphoric acid, used as the mobile phase. The flow-rate was $1 \mathrm{~mL} \mathrm{~min}^{-1}$, whereas the column temperature was $30{ }^{\circ} \mathrm{C}$. The analytes were monitored with an FL detector set at the excitation wavelength of $328 \mathrm{~nm}$ and the emission wavelength of $420 \mathrm{~nm}$, respectively. A sample volume of $10 \mu \mathrm{L}$ was injected into HPLC system.

\section{Standard Solutions}

The stock standard solutions of BM and the I.S. $\left(1 \mathrm{mg} \mathrm{mL} \mathrm{m}^{-1}\right.$ ) were prepared by weighing accurately $10.0 \mathrm{mg}$ of the compound of interest and diluting it in $10 \mathrm{~mL}$ of methanol. Standard working solutions of BM were prepared daily by diluting the stock solution appropriately with methanol, so as to obtain the concentrations of $100,10,1 \mu \mathrm{g} \mathrm{mL}^{-1}$, and $100 \mathrm{ng} \mathrm{mL}^{-1}$. The internal standard stock solution was diluted further, also with 
methanol, to prepare the working standard solution containing $10 \mu \mathrm{g} \mathrm{mL}^{-1}$ of cinoxacin. The stock and the working standard solutions of $\mathrm{BM}$ were stored at $-80^{\circ} \mathrm{C}$, while the stock standard solution of the I.S. and its working solution were stored in a refrigerator protected from light.

\section{Plasma and Urine Standards}

The calibration samples (CS) and quality control samples (QCs) were prepared in drug-free plasma $(100 \mu \mathrm{L})$ and drug-free urine $(500 \mu \mathrm{L})$ as fortified samples. The calibration plasma samples were prepared by spiking with the appropriate working standard solutions of BM to obtain ten concentration levels of $1,25,100,250,500,1000,2000$, 4000,6000 , and $8000 \mathrm{ng} \mathrm{mL}^{-1}$, and the I.S. concentration of $1500 \mathrm{ng} \mathrm{mL}^{-1}$. The plasma QCs were prepared with three BM levels $\left(25,500\right.$ and $\left.6000 \mathrm{ng} \mathrm{mL}^{-1}\right)$ at the I.S. concentration of $1500 \mathrm{ng} \mathrm{mL}^{-1}$, respectively.

To minimize the degradation of BM in urine, CS and QCs were stabilized by adding $100 \mu \mathrm{L}$ of $6 \mathrm{M} \mathrm{HCl}$ to $5 \mathrm{~mL}$ of urine prior BM spiking into the sample. In this final biological matrix, a set of calibration standards with BM levels of 5, 50, 250, 500, 1000, and $2000 \mathrm{ng} \mathrm{mL}^{-1}$ at the I.S. concentration of $1500 \mathrm{ng} \mathrm{mL}^{-1}$ was prepared. QC samples were prepared by spiking the acid-treated human urine samples with BM to produce the concentration pools of 50, 250, and $500 \mathrm{ng} \mathrm{mL}^{-1}$ at the I.S. level of $1500 \mathrm{ng} \mathrm{mL}^{-1}$.

\section{Sample Preparation}

Quality control plasma samples, calibration standard plasma samples, control blank plasma, and real clinical plasma samples were analyzed in the same manner. Thus, human plasma volumes, $100 \mu \mathrm{L}$ each, were transferred to a polypropylene centrifuge tube, and the I.S. solution at the concentration of $1500 \mathrm{ng} \mathrm{mL}^{-1}$ and different concentrations (1-8000 $\mathrm{ng} \mathrm{mL}^{-1}$ ) of BM were added, then vortexmixed for $30 \mathrm{~s}$. Next, $1 \mathrm{~mL}$ of 0.1-M hydrochloric acid was added to the plasma sample, which was then vortex-mixed for $30 \mathrm{~s}$ and shaken mechanically for $10 \mathrm{~min}$. After centrifugation for $5 \mathrm{~min}$ at $4{ }^{\circ} \mathrm{C}(8000 \mathrm{~g})$, solid-phase extraction (SPE) was performed on a LiChrolut RP-18 cartridge conditioned with $1 \mathrm{~mL}$ of methanol and $1 \mathrm{~mL}$ of water before the sample loading. Next, the cartridge was washed with $1 \mathrm{~mL}$ of $5 \%$ methanol, and vacuum dried for $1 \mathrm{~min}$. Then, the compounds of interest were eluted with $1 \mathrm{~mL}$ of methanol. The whole solvent was evaporated to dryness at $50{ }^{\circ} \mathrm{C}$ under vacuum. Finally, the residue was reconstituted with $50 \mu \mathrm{L}$ of methanol, vortex-mixed for $30 \mathrm{~s}$, and lastly added $100 \mu \mathrm{L}$ of the mobile phase. After centrifugation at $8000 \mathrm{~g}$ for $5 \mathrm{~min}$, the supernatant was transferred to a dark-colored autosampler vial, which then was stored at $2-8{ }^{\circ} \mathrm{C}$ pending analysis. Finally, a $10-\mu \mathrm{L}$ aliquot sample was injected into the LC system.

Just as above, the quality control urine samples, calibration standard urine samples, control blank urine, and real clinical urine samples were processed identically, and the final extracts were used to quantify BM. Human urine volumes, $500 \mu \mathrm{L}$ each, were transferred into a polypropylene centrifuge tube and vortex-mixed with $20 \mu \mathrm{L}$ of 6-M hydrochloric acid. Next, the I.S. solution at the concentration level of $1500 \mathrm{ng} \mathrm{mL}^{-1}$ and different concentrations of BM, ranging between 5 and $2000 \mathrm{ng} \mathrm{mL}^{-1}$ were added. After vortex-mixing for $30 \mathrm{~s}$, liquid-liquid extraction (LLE) was performed using $2 \mathrm{~mL}$ of dichloromethane. The content of the tube was vortex-mixed for $30 \mathrm{~s}$, shaken mechanically for $10 \mathrm{~min}$, and after centrifugation for $5 \mathrm{~min}$ at $4000 \mathrm{~g}$, the dichloromethane layer was quantitatively transferred into another clean glass test tube and evaporated to dryness at $45{ }^{\circ} \mathrm{C}$ under vacuum. The residue was reconstituted in $50 \mu \mathrm{L}$ of methanol and vortex-mixed for $30 \mathrm{~s}$, then followed by addition of $50 \mu \mathrm{L}$ of the mobile phase. After centrifugation at $8000 \mathrm{~g}$ for $5 \mathrm{~min}$, the supernatant was transferred to a dark-colored autosampler vial, which then was stored at $2-8{ }^{\circ} \mathrm{C}$ pending analysis. Finally, a $10-\mu \mathrm{L}$ aliquot sample was injected into the $\mathrm{LC}$ system.

\section{Validation of Analytical Methods}

The LC methods were fully validated according to the requirements of the Food and Drug Administration (FDA) and International Conference on Harmonization of Technical Requirements for Registration of Pharmaceuticals for Human Use (ICH) with emphasis laid on selectivity, linearity, sensitivity, accuracy and precision, and extraction recovery and stability $[34,35]$. This assay was performed by assaying six replicates of the calibration standards (CS) and six replications of the quality control (QC) samples prepared in three (low, middle, and high) concentration levels in human plasma and urine, respectively. In both the cases, calibrations were performed using the least-squares linear regression model in the form of $y=\mathrm{a}+\mathrm{b} x$, where $y$ is the peak area ratio of BM to the I.S. and $x$ represents the respective standard plasma/urinary concentration of BM. To evaluate linearity, pooled plasma was spiked with the working standard solutions of BM to obtain concentrations in the range of $1-8000 \mathrm{ng} \mathrm{mL}^{-1}$ at the I.S. level of $1500 \mathrm{ng} \mathrm{mL}^{-1}$, respectively. As for the urine samples, these were spiked with $\mathrm{BM}$ in the range of $5-2000 \mathrm{ng} \mathrm{mL}^{-1}$ at the I.S. concentration of $1500 \mathrm{ng} \mathrm{mL}^{-1}$, respectively. Both plasma and urine calibration samples were analyzed on the same day.

The limit of detection (LOD) was measured as the sample concentration for which the area peak was three times that of the baseline noise. The lower limit of quantification 
(LLOQ) was defined as the lowest concentration for which the ratio of the signal-to-noise was higher than 10 , and which could be analyzed with the accuracy of $\pm 20 \%$ and precision $\leq 15 \%$.

Selectivity of the method was determined by an LC analysis of six blank plasma and six urine samples of different origins for peak interference in the BM and I.S. retention times.

To assess the intra- and inter-day precision and accuracy, parallel analytical runs were performed on the same day, and on 6 days over 2 months, respectively. Therefore, intra-day precision and accuracy were measured by the sixfold replicate analysis of CS at each concentration used to prepare the calibration plots in plasma and urine, respectively. Inter-day precision and accuracy were determined by an analysis of QC samples: 25, 500, and $6000 \mathrm{ng} \mathrm{mL}^{-1}$ for BM in plasma, and 50, 250, and $500 \mathrm{ng} \mathrm{mL}^{-1}$ for BM in urine, respectively. The I.S. concentration in the plasma

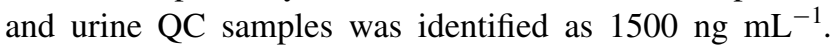
Precision was expressed as the relative standard deviation (RSD), whereas accuracy was established as the percentage difference between the measured concentration and the nominal concentration.

The absolute extraction recoveries of BM from plasma and urine were determined by comparing the peak areas of the compounds of interest in the extracted plasma and urine samples with the non-extracted ones at equivalent concentrations (100 and $1000 \mathrm{ng} \mathrm{mL}^{-1}$ for $\mathrm{BM}$, respectively). Each sample was analyzed in triplicate. The absolute recovery of the I.S. in the plasma and urine samples was determined for the concentration of $1500 \mathrm{ng} \mathrm{mL}^{-1}(n=6)$.

Several stability tests were performed as part of validation under various conditions, including short-term stability (at room temperature for $4 \mathrm{~h}$ ), long-term stability (frozen at $-80{ }^{\circ} \mathrm{C}$ for 3 months), freeze/thaw stability (three cycles from $-80{ }^{\circ} \mathrm{C}$ to room temperature), and post-preparative storage (at $4{ }^{\circ} \mathrm{C}$ for $24 \mathrm{~h}$ ), for fortified plasma and urine samples at low, medium, and high QC concentrations of BM. In each test stability assay, three replicates were analyzed using the proposed LC methods.

\section{Method Application}

The LC method was used to determine the levels of BM in human plasma and urine after intravenous infusion of the compound to a child with refractory and progressive Hodgkin's lymphoma for two consecutive days. The boy's age was 17, and his weight was $50 \mathrm{~kg}$. The condition of the patient was established through medical history, and clinical and laboratory examinations. Both the parents and the patient read the protocol and gave their written informed consent before joining the study. The clinical protocol was approved by the Ethical Committee of the Medical
University of Gdańsk (Gdańsk, Poland). BM was administered in monotherapy as a 60-min intravenous (IV) infusion at the dose of $120 \mathrm{mg}\left(\mathrm{m}^{2}\right)^{-1}$ body surface per day, for two consecutive days.

Venous blood samples $(4 \mathrm{~mL}$ each) were collected in $\mathrm{K}_{2}$ EDTA tubes at 0 (pre-dose baseline), 0.5 , and $1.0 \mathrm{~h}$ after the initiation of the first infusion, and at 1, 2, 3, 4, 6, 8, 12, 18 , and $23 \mathrm{~h}$ after the end of the first infusion. Then, blood sample collection continued over the second infusion $(0.5$ and $1 \mathrm{~h}$ ), and after $1,2,3,4,6,8,12,18,24,48$, and $72 \mathrm{~h}$ following the completion of the second BM infusion. All plasma samples were immediately separated by centrifugation at $3000 \mathrm{~g}$ for $10 \mathrm{~min}$, and the obtained plasma was stored at $-80{ }^{\circ} \mathrm{C}$ up to the $\mathrm{LC}$ analysis.

Urine samples were collected after the first IV infusion of BM (12.00 a.m.), at 14.00; 17.25; 9.50, as well as before the second IV infusion (11.50) (1st day); and after the second IV infusion (12.00 a.m.) at 14.00; 17.00; 21.40; 9.40 (2nd day), as well as at 12.00 (3rd day), and at 12.00 (4th day) after the end of drug infusion. Moreover, 24-h urine samples after day 1 and day 2 of BM administration were collected. To prevent chemical hydrolysis of BM, each urine sample $(5 \mathrm{~mL})$ was immediately frozen and stored at $-80{ }^{\circ} \mathrm{C}$ in a polypropylene tube previously treated with $100 \mu \mathrm{L}$ of $6 \mathrm{M} \mathrm{HCl}$.

\section{Results and Discussion}

In view of pharmacokinetic and biomedical studies, the aim of this study was to develop the sensitive LC methods with fluorescence detection for the quantification of $\mathrm{BM}$ in human plasma and urine to offer an interesting alternative to the LC methodologies previously reported in the literature [22, 23, 27-33]. Thus, a lot of experiments were conducted to identify the optimal conditions of sample collection and storage, to develop a simple sample preparation procedure, and to establish the chromatographic parameters for the $\mathrm{LC}$ analysis of BM in biological fluids.

\section{Method Development}

\section{Sample Collection and Storage}

The literature data on stability of nitrogen mustard-containing compounds, such as BM, indicate that the substances are unstable in aqueous solutions because of degradation by hydrolysis [36-38]. Moreover, the process is strictly $\mathrm{pH}$ dependent. For example, the BM loss was higher at $\mathrm{pH} 7.6$ than the loss levels observed at $\mathrm{pH} 6.5$, with the lowest BM degradation found at a $\mathrm{pH}<3[29,37]$. Therefore, following the literature data, various options for storing $\mathrm{BM}$ urine samples were investigated, including the addition of 6-M $\mathrm{HCl}-\mathrm{NaCl}(1-10 \mathrm{~mL}$ urine) $[22,23,28,32]$, and 100-fold 
dilution in human plasma which enabled processing and analyzing the urine-plasma samples in the same manner as the human plasma samples [29]. On the other hand, this step might also decrease the reliability of BM quantifications in urine because of a significant dilution of the real clinical sample.

In the presented study, $100 \mu \mathrm{L}$ of $6-\mathrm{M} \mathrm{HCl}$ was added to each tube prior urine sample loading $(5 \mathrm{~mL})$ to prevent chemical hydrolysis of BM. The samples were immediately frozen and stored at $-80{ }^{\circ} \mathrm{C}$ up to the $\mathrm{LC}$ analysis. This procedure can be deemed an interesting alternative to using 6-M HCl- $\mathrm{NaCl}$, because the lesser degradation of the biological matrix, combined with decreased dilution of the urine sample (1:10 vs 1:50, v/v), enables improving sensitivity and reliability of the BM assay in urine samples.

\section{Optimization of Sample Preparation}

When developing the sample preparation procedure, various organic solvents, such as tert-butyl methyl ether (TBME), ethyl acetate, and dichloromethane were used for liquid-liquid extraction (LLE) of BM from human plasma samples. Moreover, solid-phase extraction (SPE) procedures using $\mathrm{C} 18, \mathrm{C} 8$, and hydrophilic-lipophilic balance (HLB) cartridges, and three solvents for the elution of the compounds of interest (acetonitrile, methanol, and dichloromethane) were tested. The efficiency of each studied procedure was determined on the basis of the LC analysis of plasma samples spiked with BM at the levels of 100 and $1000 \mathrm{ng} \mathrm{mL}^{-1}$, then compared to the absolute recovery data calculated for other procedures studied. Moreover, signalto-noise ratios were calculated, expressed as: the area peak of the analyte in the spiked biological sample, and the signal area for the same retention time in the blank biological sample. The assay was performed to evaluate the clean-up of the matrix background. The obtained mean recovery data (mean $\pm \mathrm{SD}$ ) for BM from plasma samples are shown in Table S1 (see Electronic Supplementary Material). The results visualize that the highest efficiency of the tested LLE in plasma samples was found when dichloromethane was used as the extraction solvent $(76.6 \pm 5.4 \%)$, but the BM recovery ratio was lower than for the SPE procedures. Among the latter, the SPE methods based on a LiChrolut RP-18 cartridge were the most efficient. It was also observed that the best elimination of the ballast substances from the plasma matrix was achieved for dichloromethane (data not shown); however, the disadvantage was lower recovery of BM $(94.0 \pm 5.4 \%)$ than after the use of methanol $(99.8 \pm 3.5 \%)$. Thus, methanol was finally selected for further studies because of higher clean-up of the plasma background and the highest recovery of BM. In those SPE conditions, the rate of recovery for the I.S. was $97.5 \pm 3.8 \%$.
When optimizing the sample preparation procedure for urine samples, $20 \mu \mathrm{L}$ of $6-\mathrm{M} \mathrm{HCl}$ was added to thawed urine $(0.5 \mathrm{~mL})$ to achieve a low $\mathrm{pH}$ biological matrix, and thus minimize BM degradation. Next, all of the abovedescribed sample preparation procedures were also used. Unfortunately, the application of all studied SPE procedures brought unsatisfactory results irrespective of the urine volume loaded to the SPE cartridges $(100-500 \mu \mathrm{L})$. That was due to insufficient clean-up of the urine background from the ballast substances in the retention times of both the BM and the I.S. (data not shown). Out of the tested LLE procedures, the highest obtainable clean urine extract combined with high recovery of $\mathrm{BM}$ was found when dichloromethane was used (Electronic Supplementary Material see Table S1). In the proposed LLE method, the rate of recovery for the I.S. (cinoxacin) was $98.5 \pm 6.5 \%$.

These data evidence that the efficiency of BM extraction from plasma based on the developed SPE with C18 cartridges was higher than that of using protein precipitation with $10 \%$ perchloric acid/methanol solution (68.7-72.2\% for BM) [28], or SPE with HLB Oasis columns (76.4$82.8 \%$ for BM) [29], or protein precipitation with methanol for brain tissues (41.1-69.2\% for BM) [33]. Noteworthy, the rate of recovery of BM from urine based on LLE with dichloromethane was also higher than the rates of the methods earlier reported in the literature [29, 33]. Thus, both SPE with C18 and LLE using dichloromethane can be considered as interesting alternatives to the previous published sample preparation procedures.

\section{Optimization of LC Parameters}

For the optimization of the LC conditions for BM determination, several analytical columns like Synergi Polar-RP, Discovery HS C18, Synergi Hydro-RP, InertSustain C18, and Synergi Max-RP were tested and compared for their signal response to $\mathrm{BM}$, the peak shape, and the retention times. Finally, the Synergi Max-RP $(4.6 \mathrm{~mm} \times 150 \mathrm{~mm}$, $4 \mu \mathrm{m}$ ) column was chosen to quantify BM in human plasma and urine, because of its highest signal response to BM, its symmetric peak shape, and the acceptable retention time. This column, but having different dimensions, was also used for the quantification of BM in the presence of its metabolites described by Teichert et al. [22, 23, 32].

When the mobile phase composition was optimized, various mixtures of acetonitrile and/or methanol with water were prepared at different proportions, following which the $\mathrm{pH}$ of those mobiles phases was adjusted with $85 \%$ ortho-phosphoric acid to $2.5,2.7,2.9,3.1,3.3$, and 3.5. The mixture of acetonitrile and water in the ratio of 25:75 (v/v, $\mathrm{pH}$ 2.7) was chosen as optimal for the LC separation of $\mathrm{BM}$, since it ensures good peak separation and appropriate retention times. It should also be noted that the acidic $\mathrm{pH}$ of 
the mobile phase in the LC separation was able to prevent chemical hydrolysis of BM, whereas the isocratic elution of the mobile phase can considered as an interesting alternative to earlier described gradient mode LC methods for BM quantification in biological samples [22, 23, 27, 29-33].

Other experimental parameters, such as the column temperature and the flow-rate of the mobile phase, were also tested. Thus, increasing the column temperature and the flow-rate of the mobile phase caused shortened the retention times of the BM and the I.S., but the signal peaks of the analytes interfered with the peaks of the endogenous matrix substances. In effect, the $\mathrm{LC}$ separation at $30{ }^{\circ} \mathrm{C}$ and the flow-rate of $1 \mathrm{~mL} \mathrm{~min}{ }^{-1}$ were chosen as a good compromise between shorter retention times and the best resolution.

With the view of optimizing the fluorescence detection conditions, different excitation wavelengths (315-340 nm) and emission wavelengths $(410-435 \mathrm{~nm})$ were tested. The highest response signals for BM were observed at the excitation wavelength of $328 \mathrm{~nm}$ and emission wavelength of $420 \mathrm{~nm}$, respectively. Hence, these parameters of FL detection were finally selected for further study. Those results corroborated the data previously reported in the literature [22, 23, 28, 32].

The developed isocratic mode LC conditions for the quantification of BM in biological fluids offer satisfactory separation of $\mathrm{BM}$ at a shorter analysis run time (10 min) compared to the previously reported LC-FL techniques-70 $\min [22,23,32]$ and $14 \mathrm{~min}$ [28], respectively. This analysis time is comparable to the time obtained for the gradient mode LC-MS/MS, $11 \mathrm{~min}$ [29] and $8.2 \mathrm{~min}$ [33], but significant shorter than required for the LC-MS/ MS method with off-line radioactivity detection $(180 \mathrm{~min})$ [30], respectively. In effect, the proposed LC-FL methods can be considered as interesting alternatives for most pharmaceutical and clinical laboratories.

\section{Validation of Analytical Methods}

For method validation purposes, the calibration samples (CS) and quality control samples (QCs) were prepared as described in "Plasma and Urine Standards", and treated in the same manner as reported in "Sample Preparation", then analyzed in the LC conditions described in "Chromatographic Conditions". One of the important aspects of the validation of the method was the choice of the internal standard. For this propose, cinoxacin was selected, because this drug offers good solubility in the most organic solvents and possess natural fluorescence activity in the range required for BM. In addition, the retention time of cinoxacin was optimal in chromatographic conditions used for BM assay. Moreover, this substance is not used in human medicine.

\section{Selectivity}

Selectivity was evaluated by comparing chromatograms of drug-free blank human plasma and those of urine samples and the ones of extracts from plasma and urine containing $\mathrm{BM}$ and the I.S., respectively, all tested for interference using the proposed LC methods $(n=6)$. Representative chromatograms of drug-free plasma and plasma spiked with $500 \mathrm{ng} \mathrm{mL}^{-1}$ of $\mathrm{BM}$ and with the I.S. at the level of $1500 \mathrm{ng} \mathrm{mL}^{-1}$ are shown in Fig. 2a and b, respectively. Typical chromatograms of drug-free urine and urine spiked with $500 \mathrm{ng} \mathrm{mL}^{-1}$ of BM and with the I.S. at the concentration of $1500 \mathrm{ng} \mathrm{mL}^{-1}$ are presented in Fig. 3a and b, respectively. The chromatograms confirm that no interferences were detected from the substances of the endogenous matrix in the area, where BM and the I.S. appear.

\section{Linearity}

The linearity of the method was confirmed over the concentration ranges of $1-8000$ and $5-2000 \mathrm{ng} \mathrm{mL}^{-1}$ for $\mathrm{BM}$ in plasma and urine, respectively. The corresponding calibration parameters of both calibration curves are summarized in Table 1. The data confirm that the calibration curves demonstrated good linearity for both plasma and urine, with the correlation coefficients $\left(R^{2}\right)$ higher than 0.9996, which indicate excellent linearity of the methods within the considered linear ranges.

\section{Limits of Detection and Quantification}

The limits of detection (LOD) were measured for six independently made replications and were found to be 0.5 and $2.5 \mathrm{ng} \mathrm{mL} \mathrm{m}^{-1}$ for $\mathrm{BM}$ in plasma and urine, respectively. The lower limits of quantification (LLOQ) for BM were estimated by the six-fold replicate analysis, and found to stay at the level of 1 and $5 \mathrm{ng} \mathrm{mL} L^{-1}$ in plasma and urine samples, respectively. The LLOQ for BM were also the lowest standard concentrations in both calibration curves (Table 1). The LLOQ parameters were lower than those published heretofore for the LC-FL assay of BM in plasma [28], LC-MS/MS determination in urine [27, 29], and mouse brain tissue [33], while being comparable to those obtained by LC-FL for BM in urine [28], even though lower plasma and urine volumes were used (100 vs 200 $250 \mu \mathrm{L}$ for plasma and 500 vs $1000 \mu \mathrm{L}$ for urine, respectively) [22, 23, 28, 29, 32].

\section{Precision and Accuracy}

The intra-day and inter-day precision and accuracy results for both the LC methods are summarized in Table 2. The data confirmed that intra-day precisions for BM in plasma 
Fig. 2 Typical chromatograms of the blank human plasma extract (a) and of a plasma sample spiked with BM (1) (500 ng mL $\left.\mathrm{mL}^{-1}\right)$ and cinoxacin (I.S.) at the level of $1500 \mathrm{ng} \mathrm{mL}^{-1}$ (b) after the SPE using the $\mathrm{C} 18$ cartridges
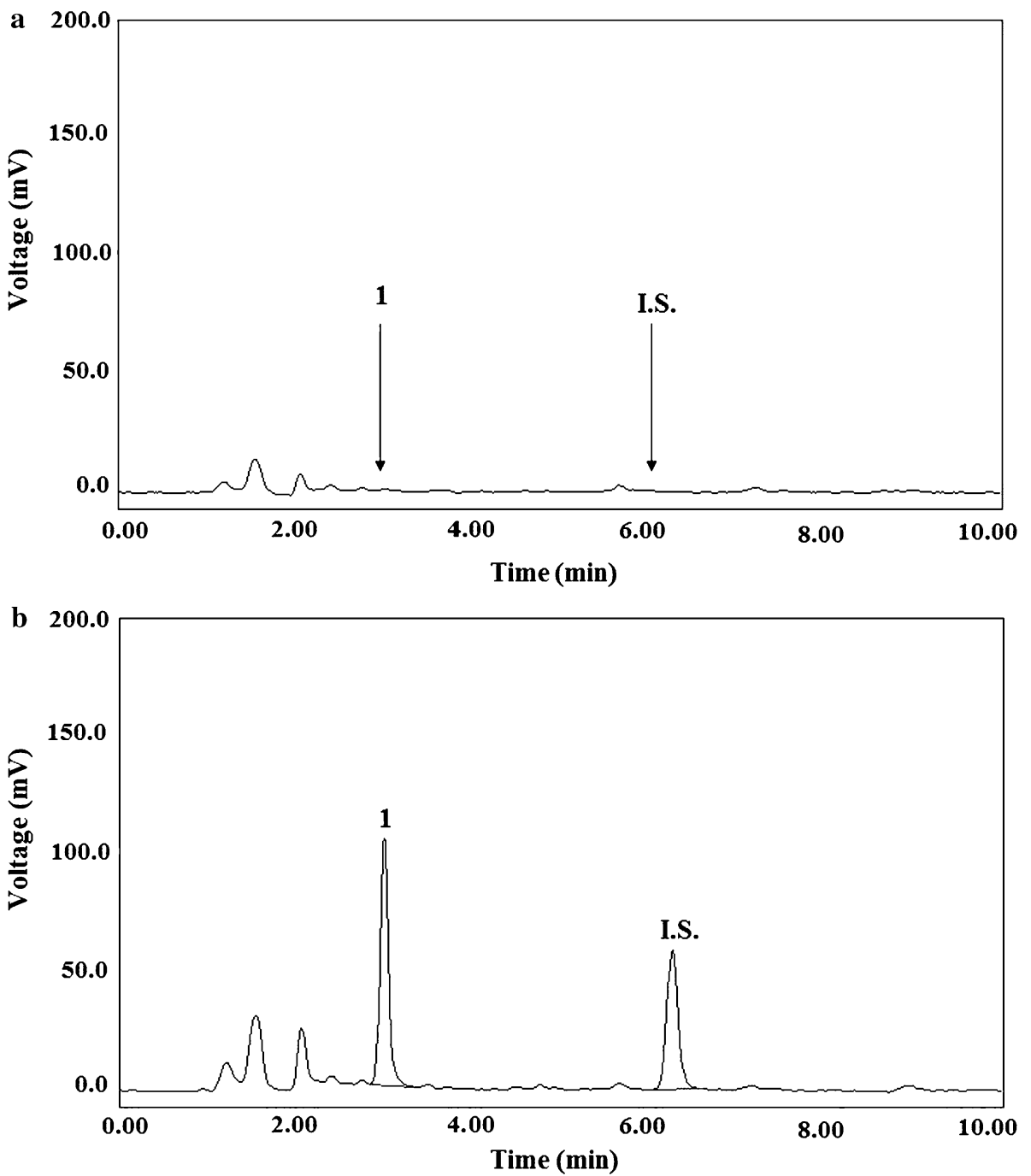

and urine were below 9.65 and $9.86 \%$, while intra-day accuracies were higher than 92.63 and $94.29 \%$, respectively. The inter-day precisions did not exceed 9.82 and $9.02 \%$. The inter-day accuracies ranged from 100.26 to $101.16 \%$ and between 99.75 and $101.74 \%$, respectively. Those data confirmed that the intra-day and inter-day accuracy and precision values met the generally accepted criteria for bioanalytical method validation at all calibration and QC concentration levels [34, 35].

\section{Recovery}

The extraction recoveries of BM from plasma and urine were measured at two different concentration levels (low and high), six replicates for each concentration. The obtained recovery data for BM are summarized in Table S1 (see Electronic Supplementary Material). The I.S. (cinoxacin) recovery rate from human plasma using SPEC18 was attained at $97.5 \pm 3.8 \%$, whereas the value of $98.5 \pm 6.5 \%$ was calculated for the urine sample after the
LLE with dichloromethane. These extraction recovery data confirm that the developed sample preparation procedures can assure adequate sensitivity for processing plasma and urine samples for the LC assay of BM. Moreover, these procedures are more effective than the previously reported methods [28, 29, 33].

\section{Stability Tests}

Stability tests for various conditions, as described in the section "Validation of Analytical Methods", were conducted by assessing plasma and urine samples at three QC levels of BM. Representative chromatograms of plasma spiked with $500 \mathrm{ng} \mathrm{mL}^{-1}$ of BM and with the I.S. at the level of $1500 \mathrm{ng} \mathrm{mL}^{-1}$ obtained in short-term stability and long-term stability tests are shown in Fig. S1a and S1b, whereas the chromatograms performed in freeze/thaw stability and post-preparative storage tests are presented in Figure S2c and S2d, respectively (see Electronic Supplementary Material). Typical chromatograms of urine spiked 
Fig. 3 Typical chromatograms of the blank human urine extract (a) and of a urine sample spiked with $\mathrm{BM}$ (1) (500 $\left.\mathrm{ng} \mathrm{mL}^{-1}\right)$ and cinoxacin (I.S.) at the level of $1500 \mathrm{ng} \mathrm{mL}^{-1}$ (b) after the LLE with dichloromethane
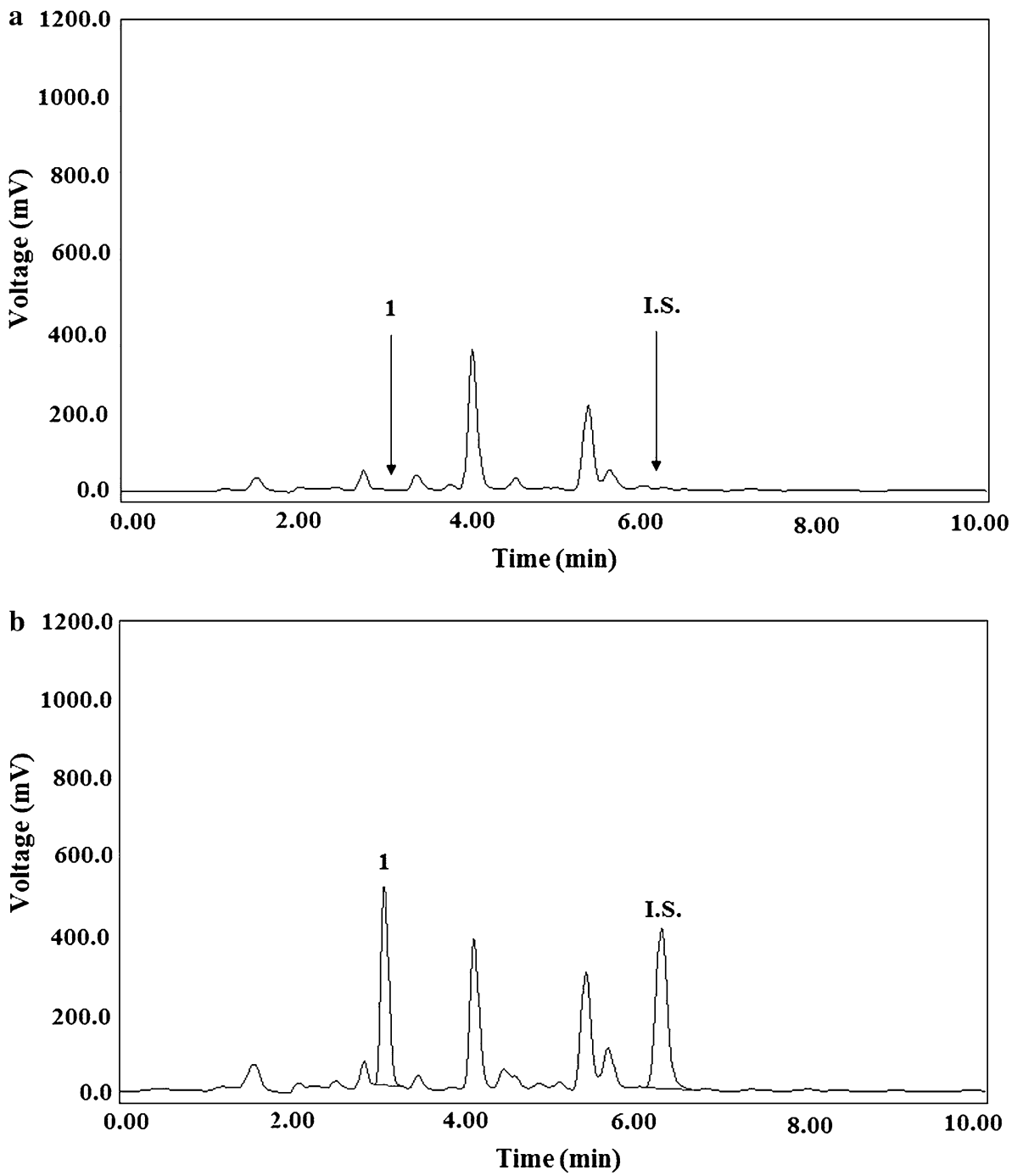

Table 1 Summary of validation data for BM determination in human plasma and urine by the LC-FL methods $(n=6)$

\begin{tabular}{lll}
\hline & Plasma & Urine \\
\hline Linearity $\left(\mathrm{ng} \mathrm{mL}^{-1}\right)$ & $1-8000$ & $5-2000$ \\
Equation parameter & & \\
$\quad$ Slope & $0.0040 \pm 0.00002$ & $0.0021 \pm 0.00002$ \\
Intercept & $0.0127 \pm 0.0620$ & $-0.0043 \pm 0.0201$ \\
Standard error & 0.152 & 0.0363 \\
Correlation coefficient & 0.9998 & 0.9996 \\
$\quad\left(R^{2}\right)$ & & \\
LOD $\left(\mathrm{ng} \mathrm{mL}^{-1}\right)$ & 0.5 & 2.5 \\
LLOQ $\left(\mathrm{ng} \mathrm{mL}^{-1}\right)$ & 1.0 & 5.0 \\
\hline
\end{tabular}

with $250 \mathrm{ng} \mathrm{mL} \mathrm{mL}^{-1}$ of $\mathrm{BM}$ and with the I.S. at the level of $1500 \mathrm{ng} \mathrm{\textrm {mL } ^ { - 1 }}$ obtained in four stability tests are illustrated in Figs. S3 and S4, respectively (see Electronic Supplementary Material). All stability evaluations were based on back-calculated concentrations. The resulting data are summarized in Table 3 revealed no significant degradation of BM in the plasma and urine samples. Thus, all samples prove stable and could be handled in normal laboratory conditions without any significant loss, if under the conditions described above.

\section{Method Application to the Real Plasma and Urine Samples}

It should be noticed that clinical trials on the application of $\mathrm{BM}$ in cancer children are seldom reported which causes higher risk of incorrect drug administration [24, 25]. In effect, the efficacy of the therapy and high level of adverse effects can be observed [26].

The developed LC methods have been successfully used in monitoring of BM administered to a 17-year-old boy with refractory progressive Hodgkin's lymphoma, in the form of 60 -min IV infusions at a dose of $120 \mathrm{mg}\left(\mathrm{m}^{2}\right)^{-1}$ body surface each, on two consecutive days. The representative LC 
Table 2 Intra-day and inter-day precision and accuracy for the determination of BM in plasma and urine samples by SPE-LC and LLE-LC techniques, respectively

\begin{tabular}{|c|c|c|c|c|c|c|c|}
\hline \multicolumn{4}{|c|}{ Intra-day $(n=6)$} & \multicolumn{4}{|c|}{ Inter-day $(n=6)$} \\
\hline \multicolumn{2}{|c|}{ Concentration $\left(\mathrm{ng} \mathrm{mL}^{-1}\right)$} & \multirow{2}{*}{$\begin{array}{l}\text { Precision } \\
\text { RSD }(\%)\end{array}$} & \multirow{2}{*}{$\begin{array}{l}\text { Accuracy } \\
(\%)\end{array}$} & \multicolumn{2}{|c|}{ Concentration $\left(\mathrm{ng} \mathrm{mL}^{-1}\right)$} & \multirow{2}{*}{$\begin{array}{l}\text { Precision } \\
\text { RSD (\%) }\end{array}$} & \multirow{2}{*}{$\begin{array}{l}\text { Accuracy } \\
(\%)\end{array}$} \\
\hline Spiked & Found (mean $\pm \mathrm{SD})$ & & & Spiked & Found (mean $\pm \mathrm{SD})$ & & \\
\hline \multicolumn{8}{|l|}{ Plasma } \\
\hline 1 & $1.08 \pm 0.10$ & 9.65 & 107.92 & 25 & $25.29 \pm 2.48$ & 9.82 & 101.16 \\
\hline 25 & $24.08 \pm 2.06$ & 8.54 & 96.30 & 500 & $501.28 \pm 5.64$ & 1.12 & 100.26 \\
\hline 100 & $106.58 \pm 7.75$ & 7.27 & 106.58 & 6000 & $6018.21 \pm 48.73$ & 0.81 & 100.30 \\
\hline 250 & $231.58 \pm 13.42$ & 5.79 & 92.63 & & & & \\
\hline 500 & $489.08 \pm 23.93$ & 4.89 & 97.82 & & & & \\
\hline 1000 & $1034.08 \pm 38.50$ & 3.72 & 103.41 & & & & \\
\hline 2000 & $2049.08 \pm 41.50$ & 2.03 & 102.45 & & & & \\
\hline 4000 & $3926.58 \pm 62.91$ & 1.60 & 98.16 & & & & \\
\hline 6000 & $6049.08 \pm 66.24$ & 1.10 & 100.82 & & & & \\
\hline 8000 & $8029.08 \pm 43.99$ & 0.55 & 100.36 & & & & \\
\hline \multicolumn{8}{|l|}{ Urine } \\
\hline 5 & $4.71 \pm 0.46$ & 9.86 & 94.29 & 50 & $49.87 \pm 4.50$ & 9.02 & 99.75 \\
\hline 50 & $49.19 \pm 4.23$ & 8.59 & 98.38 & 250 & $254.34 \pm 10.47$ & 4.12 & 101.74 \\
\hline 250 & $249.67 \pm 15.94$ & 6.38 & 99.87 & 500 & $505.49 \pm 3.73$ & 0.74 & 101.10 \\
\hline 500 & $487.76 \pm 19.98$ & 4.10 & 97.55 & & & & \\
\hline 1000 & $1035.38 \pm 24.28$ & 2.35 & 103.54 & & & & \\
\hline 2000 & $2002.05 \pm 31.15$ & 1.56 & 100.10 & & & & \\
\hline
\end{tabular}

Than $9.86 \%$ while the accuracies were in the range of 92.63-107.92 and $94.29-103.54 \%$

Table 3 Stability of BM in plasma and urine samples $(n=3)$

\begin{tabular}{|c|c|c|c|}
\hline \multirow[t]{3}{*}{ Plasma } & \multicolumn{3}{|c|}{ Concentration $\left(\mathrm{ng} \mathrm{mL}^{-1}\right)$} \\
\hline & 25 & 500 & 6000 \\
\hline & \multicolumn{3}{|c|}{ Accuracy $($ mean \pm SD) $(\%)$} \\
\hline Short-time stability & $97.7 \pm 7.8$ & $101.7 \pm 5.5$ & $102.1 \pm 6.8$ \\
\hline Long-time stability & $109.9 \pm 6.9$ & $95.9 \pm 3.9$ & $98.1 \pm 8.9$ \\
\hline Freeze/thaw stability & $95.7 \pm 6.7$ & $102.6 \pm 8.1$ & $96.6 \pm 7.8$ \\
\hline Post-preparative storage & $103.9 \pm 3.9$ & $98.3 \pm 6.9$ & $101.2 \pm 7.9$ \\
\hline \multirow[t]{3}{*}{ Urine } & \multicolumn{3}{|c|}{ Concentration $\left(\mathrm{ng} \mathrm{mL}^{-1}\right)$} \\
\hline & 50 & 250 & 500 \\
\hline & \multicolumn{3}{|c|}{ Accuracy $($ mean \pm SD) $(\%)$} \\
\hline Short-time stability & $103.4 \pm 4.9$ & $102.9 \pm 7.9$ & $96.6 \pm 6.6$ \\
\hline Long-time stability & $104.3 \pm 8.8$ & $94.7 \pm 5.5$ & $97.9 \pm 4.1$ \\
\hline Freeze/thaw stability & $93.9 \pm 3.9$ & $96.9 \pm 3.9$ & $95.9 \pm 3.9$ \\
\hline Post-preparative storage & $99.7 \pm 4.4$ & $101.3 \pm 6.6$ & $101.7 \pm 7.3$ \\
\hline
\end{tabular}

chromatograms of the plasma and urine extracts obtained from the patient after the first IV BM infusion are shown in Fig. $4 \mathrm{a}-\mathrm{c}$, respectively. The calculated profile of the plasma concentration-time for BM is presented in Fig. 5a, while the urinary concentrations of BM collected during and after the IV drug infusion are shown in Fig. 5b, respectively.
Thus, according to the plasma profile of BM, $C_{\max }$ at the level of $7015.3 \pm 34.5$ and $7245.4 \pm 42.8 \mathrm{ng} \mathrm{mL}^{-1}$ for BM was observed at time of the first and the second IV infusion $\left(T_{\max }=1 \mathrm{~h}\right)($ Fig. 5a). This BM profile obtained in our patient is comparable to the profiles previously reported for pediatric patients after an IV infusion of BM at the dose 
Fig. 4 Representative LC chromatograms of human extracts obtained from a

17-year-old patient with refractory progressive Hodgkin's lymphoma, after IV infusions at the dose of $120 \mathrm{mg}\left(\mathrm{m}^{2}\right)^{-1}$ body surface per day, administered for two consecutive days at the following BM levels (1): a $7015.36 \mathrm{ng} \mathrm{mL}^{-1}$ in the plasma sample collected after the end of the first IV infusion; b $487.37 \mathrm{ng} \mathrm{mL}^{-1}$ in the plasma sample collected $1 \mathrm{~h}$ after the end of the first IV infusion; and c $13.18 \mathrm{ng} \mathrm{mL}^{-1}$ in the urine sample collected at 21.40 after the second IV infusion (12.00 a.m.), and cinoxacin (I.S.) at the concentration of $1500 \mathrm{ng} \mathrm{mL}^{-1}$
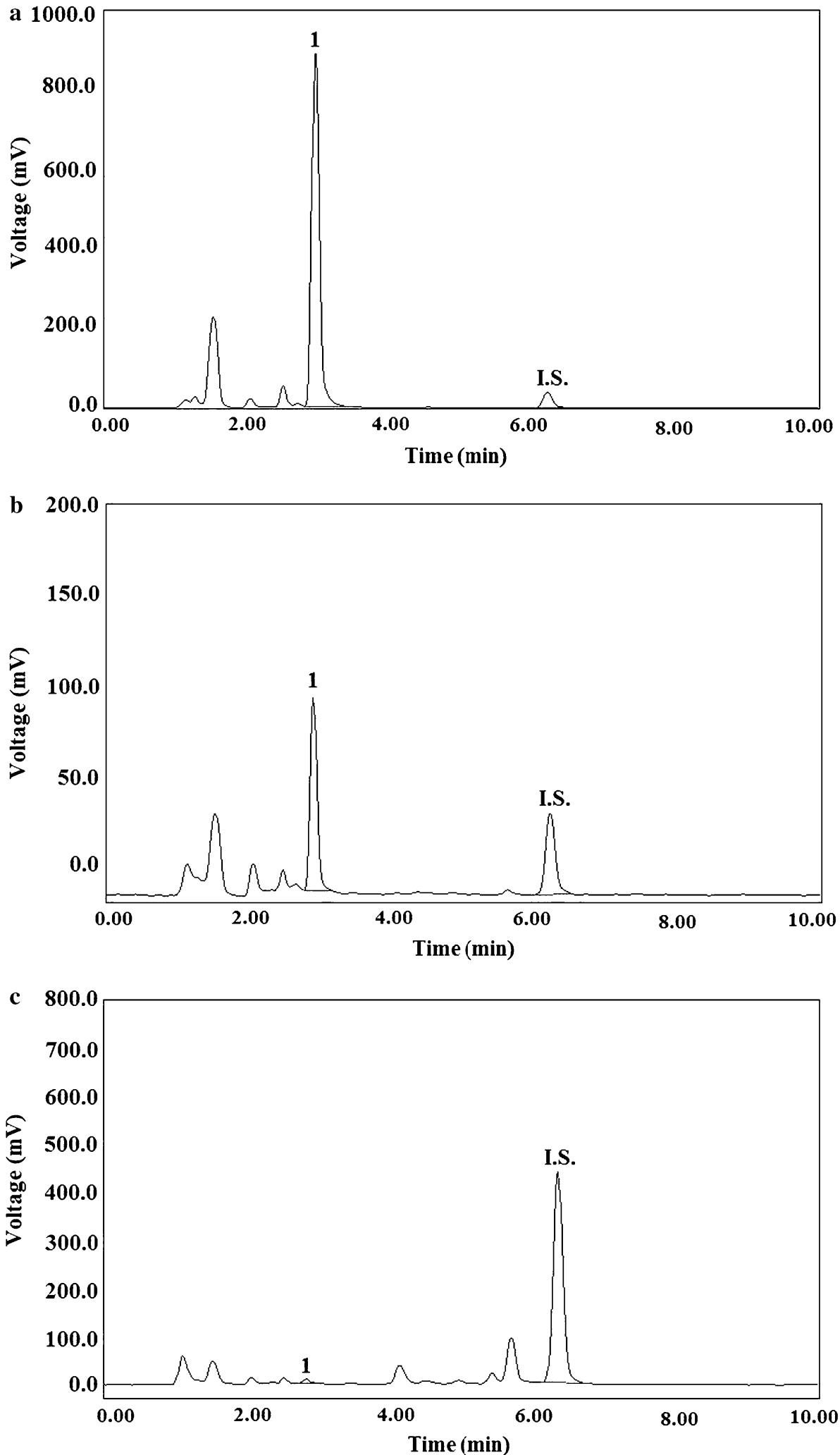

of $120 \mathrm{mg}\left(\mathrm{m}^{2}\right)^{-1}[24,25]$. Urinary concentrations of BM were significantly lower than those observed in plasma (Fig. 5b), what confirms that this drug undergoes extensive metabolism. Specifically, the BM concentrations of 11.3 and $7.3 \mathrm{ng} \mathrm{mL}{ }^{-1}$ were found in 24-h urine samples after the first and the second IV BM infusion, respectively. The results stay in line with the previously reported literature data [23-25, 27-29]. 

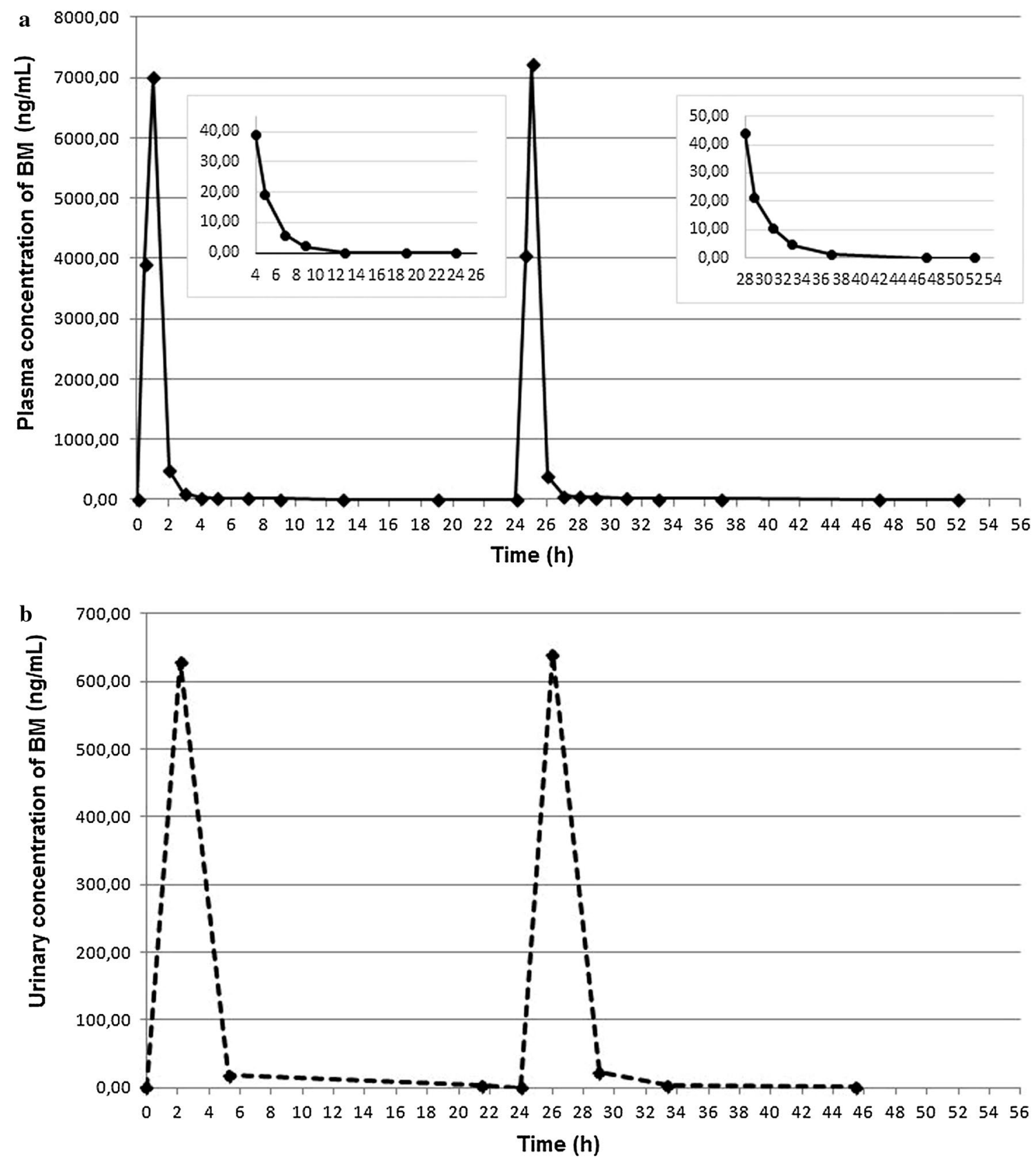

Fig. 5 BM concentration profiles in the plasma (a) and urine (b) of a 17-year-old patient with NHL, after IV infusions at the dose of 120 mg $\left(\mathrm{m}^{2}\right)^{-1}$ body surface per day, administered for two consecutive days

\section{Conclusions}

In brief, fast, precise, and accurate LC-FL methods for quantification of $\mathrm{BM}$ in human plasma and urine, where cinoxacin was used as the internal standard, were developed and validated. As concerns plasma samples, the sample preparation procedure involved the application of the SPE with C18 cartridges, while a one-step LLE with dichloromethane was applied for the extraction of BM from urine. In both the cases, the LC analysis of BM was carried out on the Synergi Max-RP in the isocratic mode. The proposed methods are time-saving and economical; furthermore, they are suitable for analyzing large numbers of plasma and urine samples for drug monitoring, pharmacokinetic, and biomedical investigations. Finally, the present LC-FL techniques have been successfully used for the monitoring of BM after an IV infusion of BM to a child with refractory progressive Hodgkin's lymphoma. 
Acknowledgments This project was supported by the Ministry of Science and Higher Education of the Republic of Poland, from the quality - promoting subsidy, under the Leading National Research Centre (KNOW) programme for the years 2012-2017.

\section{Compliance with Ethical Standards}

Conflict of interest The authors declare that they have no conflict of interest.

Open Access This article is distributed under the terms of the Creative Commons Attribution 4.0 International License (http://creativecommons.org/licenses/by/4.0/), which permits unrestricted use, distribution, and reproduction in any medium, provided you give appropriate credit to the original author(s) and the source, provide a link to the Creative Commons license, and indicate if changes were made.

\section{References}

1. Leoni LM, Bailey B, Reifert J, Bendall HH, Zeller RW, Corbeil J, Elliott G, Niemeyer CC (2008) Bendamustine (Treanda) displays a distinct pattern of cytoxicity and unique mechanistic features compared with other Alkylating agents. Clin Cancer Res 14:309-317

2. Bergmann MA (2006) Efficacy of bendamustine in patients with relapsed or refractory chronic lymphocytic leukemia: results of a phase I/II study of the German CL Study Group. Haematologica 90:1357-1364

3. Ponisch W, Mitrou PS, Merkle K, Herold M, Assmann M, Wilhelm G, Dachselt K, Richter P, Shirmer V (2006) Treatment of bendamustine and prednisone in patients with newly diagnosed multiple myeloma results in superior complete response rate, prolonged time to treatment failure and improved quality of life compared to treatment with melphalan and prednisone-a randomized phase III study of the East German Study Group of Hematology and Oncology (OSHO). J Cancer Res Clin Oncol 132:205-212

4. Kalaycio M (2008) Clinical experience with Bendamustine: a new treatment for patients with chronic lymphocytic leukemia. Clin Leuk 2:223-229

5. Robinson KS, Williams ME, van der Jagt RH, Cohen P, Herst JA, Tulpule A, Schwarzberg LS, Lemieux B, Cheson BD (2008) Phase II multicenter study of bendamustine plus rituximab in patients with relapsed indolent B-cell and mantle cell non-Hodgkin's lymphoma. J Clin Oncol 26:4473-4479

6. Chow KU, Boehrer S, Geduldig K, Krapohl A, Hoelzer D, Mitrou PS, Weidmann E (2001) In vitro induction of apoptosis of neoplastic cells in low-grade non-Hodgkin's lymphomas using combinations of established cytotoxic drugs with bendamustine. Haematologica 86:485-493

7. Schwänen C, Hecker T, Hübinger G, Wölfle M, Rittgen W, Bergmann L, Karakas T (2002) In vitro evaluation of bendamustine induced apoptosis in B chronic lymphocytic leukemia. Leukemia 16:2096-2105

8. Bottke D, Bathe K, Wiegel T, Hinkelbein W (2007) Phase I trial of radiochemotherapy with bendamustine in patients with recurrent squamous cell carcinoma of the head and neck. Strahlenther Onkol 183:128-132

9. Rasschaert M, Schrijvers D, Van den BJ, Dyck J, Bosmans J, Merkle K, Vermorken JB (2007) A phase I study of bendamustine hydrochloride administered day $1+2$ every 3 weeks in patients with solid tumors. Br J Cancer 96:1692-1698
10. Glode AE, Jarkowski A (2009) Bendamustine: a new treatment option for chronic lymphocytic leukemia. Pharmacotherapy 29:1375-1384

11. Konstantinov SM, Kostovski A, Topashka-Ancheva M, Genova M, Berger MR (2002) Cytotoxic efficacy of bendamustine in human leukemia and breast cancer cell lines. J Cancer Res Clin Oncol 128:271-278

12. Owen JS, Melhem M, Passarell JA, D'Andrea D, Darwish M (2010) Bendamustine pharmacokinetic profile and exposureresponse relationships in patients with indolent non-Hodgkin's lymphoma. Caner Chemother Pharmocol 66:1039-1049

13. Schmittel A, Knodler M, Hortig P, Schulze K, Thiel E, Keilholz U (2007) Phase II trial of second-line bendamustine chemotherapy in relapsed small cell lung cancer patients. Lung Cancer 55:109-113

14. Strumberg D, Harstrick A, Doll K, Hoffman B, Seeber S (1996) Bendamustine hydrochloride activity against doxorubicin resistent human breast carcinoma cell lines. Anticancer Drugs 7:415-421

15. Hartman JT, Mayer F, Schleicher J, Horger M, Huober J, Meisinger I, Pintoffl J, Käfer G, Kanz L, Grünwald V (2007) Bendamustine hydrochloride in patients with refractory soft tissue sarcoma: a noncomparative multicenter phase 2 study of the German Sarcoma Group (AIO-001). Cancer 110:861-866

16. Gandhi V (2002) Metabolism and mechanisms of action of bendamustine: Rationales for combination therapies. Semin Oncol 29(4 Suppl 13):4-11

17. von Minckwitz G, Chernozemsky I, Sirakova L, Chilingirov P, Souchon R, Marschner N, Kleeberg U, Tsekov C, Fritze D, Thomassen C, Stuart N, Vermorken JB, Loibl S, Merkle K, Kaufmann M (2005) Bendamustine prolongs progression-free survival in metastatic breast cancer (MBC): a phase III prospective, randomized, multicenter trial of bendamustine hydrochloride, methotrexate and 5-fluorouracil (BMF) versus cyclophosphamide, methotrexate and 5-fluorouracil (CMF) as first-line treatment of MBC. Anticancer Drugs 16:871-877

18. Rummel MJ, Al-Batran SE, Kim SZ, Welslau M, Hecker R, Kofahl-Krause D, Josten KM, Dürk H, Rost A, Neise M, von Grünhagen U, Chow KU, Hansmann ML, Hoelzer D, Mitrou PS (2005) Bendamustine plus rituximab is effective and has a favorable toxicity profile in the treatment of mantle cell and lowgrade non-Hodgkin's lymphoma. J Clin Oncol 23:3383-3389

19. Robinson KS, Williams ME, van der Jagt RH, Cohen P, Herst JA, Tulpule A, Schwartzberg LS, Lemieux B, Cheson BD (2008) Phase II Multicenter Study of Bendamustine Plus Rituximab in Patients With Relapsed Indolent B-Cell and Mantle Cell NonHodgkin's Lymphoma. J Clin Oncol 26:4473-4479

20. Darwish M, Bond M, Hellriegel E, Robertson P, Chovan JP Jr (2015) Pharmacokinetic and pharmacodynamic profile of bendamustine and its metabolites. Cancer Chemother Pharmacol 75:1143-1154

21. Dubbelman A, Rosing H, Darwish M, D’Andrea D, Bond M, Hellriegel E, Robertson P, Beijnen JH, Schellens JHM (2013) Pharmacokinetics and excretion of C14-bendamustine in patients with relapsed or refractory malignancy. Drugs 13:17-28

22. Teichert J, Baumann F, Chao Q, Franklin C, Bailey B, Hennig L (2007) Characterization of two phase I metabolites of bendamustine in human liver microsomes and in cancer patients treated with Bendamustine hydrochloride. Cancer Chemother Pharmacol 59:759-770

23. Teichert J, Sohr R, Baumann F, Hennig L, Merkle K, Caca K, Preiss R (2005) Synthesis and characterization of some new phase II metabolites of the alkylator Bendamustine and their identification in human bile, urine, and plasma from patients with cholangiocarcinoma. Drug Metab Dispos 33:984-992 
24. Fraser C, Brown P, Megason G, Ahn HS, Cho B, Kirov I, Frankel L, Aplenc R, Bensen-Kennedy D, Munteanu M, Weaver J, Hatker-Murray P (2014) Open-label bendamustine monotherapy for pediatric patients with relapsed or refractory acute leukemia: efficacy and tolerability. J Pediatr Hematol Oncol 36:e212-e218

25. Darwish M, Megason G, Bond M, Hellriegel E, Robertson P Jr, Grasela T, Phillips L (2014) Population pharmacokinetics and pharmacokinetics/pharmacodynamics of bendamustine in pediatric patients with relapsed/refractory acute leukemia. Curr Med Res Opin 30:2305-2315

26. Cheson BD, Wendtner C, Pieper A, Dreyling M, Friedberg J, Hoelzer D (2010) Optimal use of bendamustine in chronic lypmhocytic leukemia, non-Hodgkin lymphomas and multiple myeloma: treatment recommendations from an an international consensus panel. Clin Lymphoma Myeloma Leuk 10:21-27

27. Ogura M, Uchida T, Taniwaki M, Ando K, Watanabe T, Kasai M, Matsumoto Y, Shimizu D, Ogawa Y, Ohmachi K, Yokoyama H, Tobinai K (2010) Phase I and pharmacokinetic study of bendamustine hydrochloride in relapsed or refractory indolent B-cell non-Hodgkin lymphoma and mantle cell lymphoma. Cancer Sci 101:2054-2058

28. Xie F, Cheng Z, Cheng H, Yu P (2014) Simultaneous determination of bendamustine and its active metabolite, gammahydroxy-bendamustine in human plasma and urine using HPLCfluorescence detector: application to a pharmacokinetic study in Chinese cancer patients. J Chromatogr B 960:98-104

29. Dubbelman AC, Tibben M, Rosing H, Gebretensae A, Nan L (2012) Development and validation of LC-MS/MS assays for the quantification of bendamustine and its metabolites in human plasma and urine. J Chromatogr B 893:92-100

30. Dubbelman AC, Jansen RS, Rosing H, Darwish M, Hellriegel E, Robertson P Jr, Schellens JHM, Beijnen JH (2012) Metabolite profiling of bendamustine in urine of cancer patients after administration of [14C]bendamustine. Drug Metab Dispos 40:1297-1307

31. Chovan JP, Li F, Yu E, Ring SC (2007) Metabolic profile of [14C]bendamustine in rat urine and bile: preliminary structural identification of metabolites. Drug Metab Dispos 35:1744-1753

32. Teichert J, Sohr R, Hennig L, Baumann F, Schoppmeyer K, Patzak U, Preiss R (2009) Identification and quantitation of the $\mathrm{N}$-acetyl-L-cysteine $S$-conjugates of bendamustine and its sulfoxides in human bile after administration of bendamustine hydrochloride. Drug Metab Dispos 37:292-301

33. He L, Grecula JC, Ling Y, Enzerra MD, Ammirati M, Kendra K (2012) Development and validation of sensitive liquid chromatography/tandem mass spectrometry method for quantification of bendamustine in mouse brain tissue. J Chromatogr B 905:141-144

34. FDA Guidance for Industry Bioanalytical Method Validation (2001) US Department of Health and Human Service, Food and Drug Administration, Center for Drug Evaluation and Research (CDER)

35. ICH Validation of analytical procedures: Text and methodology 2(R1) (2005) International Conference on Harmonization

36. Annapurna MM, Venkatesh B, Anusha S, Neelima B (2012) Stability-indicating liquid chromatographic method for the determination of bendamustine hydrochloride in parenterals. Res $\mathbf{J}$ Chem Sci 2:72-78

37. Pencheva I, Bogomilova A, Koseva N, Obreshkova D, Troev K (2008) HPLC study on the stability of bendamustine hydrochloride immobilized onto poliphosphoesters. J Pharm Biomed Anal 48:1143-1150

38. Kasa S, Reddy MRS, Kadaboina RS, Murki V, Mulukutla VS (2014) Stability-Indicating LC Method for the Estimation of Bendamustine Hydrochloride and its Related Impurities. J Chromatogr Sci 52:573-583 